\title{
First molecular characterization of Cryptosporidium and Giardia from bovines (Bos taurus and Bubalus bubalis) in Sri Lanka: unexpected absence of $C$. parvum from pre-weaned calves
}

Harshanie Abeywardena' ${ }^{1}$ Aaron R Jex ${ }^{1}$, Anson V Koehler ${ }^{1}$, RPV Jayanthe Rajapakse², Kanchana Udayawarna², Shane R Haydon ${ }^{3}$, Melita A Stevens ${ }^{3}$ and Robin B Gasser ${ }^{1 *}$

\begin{abstract}
Background: The genetic characterization of Cryptosporidium and Giardia has important implications for investigating their epidemiology and underpins their control. We undertook the first molecular epidemiological survey of domestic bovids in selected regions of Sri Lanka to establish whether they excreted Cryptosporidium and/or Giardia with zoonotic potential.

Methods: Faecal samples were collected from dairy calves ( $n=340$; Bos taurus; $<3$ months of age; weekly sampling for six weeks) and water buffaloes ( $n=297$; Bubalus bubalis; $<6$ months and $\geq 6$ months of age; one sampling) from seven different farms in Sri Lanka. Genomic DNAs were extracted from individual faecal samples and then tested for the presence of parasite DNA using a PCR-based mutation scanning-targeted sequencingphylogenetic approach, employing genetic markers within the small subunit of nuclear ribosomal RNA and $60 \mathrm{kDa}$ glycoprotein genes (designated pSSU and pgp60, respectively) for Cryptosporidium, and within the triose phosphate isomerise (ptpi) gene for Giardia.
\end{abstract}

Results: Based on pSSU sequence data, C. bovis, C. ryanae and six new genotypes that were genetically similar but not identical to $C$. andersoni $(n=1), C$. bovis $(n=1), C$. ryanae $(n=3)$ and C. suis $(n=1)$ were recorded in cattle. For pSSU, two other, new genotypes were defined in water buffalo, which were genetically most similar to Cryptosporidium genotypes recorded previously in this host species in other countries including Australia. Consistent with the findings for pSSU, no species or genotypes of Cryptosporidium with zoonotic potential were detected using pgp60. Based on ptpi sequence data, G. duodenalis assemblages A and E were detected in four and 137 samples from cattle, respectively, and assemblage $E$ in two samples from water buffaloes.

Conclusions: The present study showed that C. parvum, the most commonly reported zoonotic species of Cryptosporidium recognised in bovine calves globally, was not detected in any of the samples from pre-weaned calves tested in the present study. However, eight new genotypes were recorded. Future studies of different host species in various regions are required to investigate the molecular epidemiology of cryptosporidiosis and giardiasis in Sri Lanka and neighbouring countries in South Asia.

Keywords: Bos taurus, Bubalus bubalis, Cryptosporidium, Giardia, Single-strand conformation polymorphism (SSCP) analysis, Restriction endonuclease fingerprinting (REF), Sri Lanka

\footnotetext{
*Correspondence: robinbg@unimelb.edu.au

${ }^{1}$ Faculty of Veterinary Science, The University of Melbourne, Parkville, Victoria,

Australia

Full list of author information is available at the end of the article
} 


\section{Background}

Cryptosporidium and Giardia are two parasitic protists that mainly infect the gastrointestinal tract and cause enteric disease in humans and various other animals $[1,2]$. These protozoa are global in their distribution and adversely impact on human health in both developed and developing countries $[3,4]$. Infections are usually transmitted via the faecal-oral route, following direct or indirect contact with infective stages (oocysts or cysts) [2,3]. Although infections are often self-limiting in immuno-competent individuals $[3,5]$, they can become severe and chronic in infants, elderly people or immuno-compromised or -suppressed individuals [6-8]. Key risk factors for cryptosporidiosis and giardiasis of humans include contact with individuals with diarrhoea, swimming in public pools, travel to developing countries and, importantly, direct contact with animals (e.g., [9-12]).

Cryptosporidiosis and giardiasis can be transmitted from human to human (anthroponotic) or from animal to human (zoonotic) [13]. Ruminants often have been implicated as a major source of human cryptosporidiosis and giardiasis based on the findings of many molecular epidemiological studies (reviewed in $[14,15]$ ). For instance, investigations of outbreaks and case-control studies [16-20] have demonstrated that there is a strong link between human cryptosporidiosis/giardiasis and the direct or indirect contact with cattle, particularly pre-weaned calves $[15,21]$. To date, seven species (i.e. $C$. andersoni, C. bovis, C. felis, C. hominis, C. parvum, C. ryanae and $C$. suis) and two genotypes of Cryptosporidium (i.e. "pig genotype II" and a new "C. suis-like genotype") have been recorded in cattle [22,23]. For Giardia duodenalis, assemblage $\mathrm{E}$ is the most commonly reported genotype in cattle, followed by assemblages A and B [24-26]. An appraisal of the literature shows that the majority of molecular studies of Cryptosporidium and Giardia of cattle and other animals relates mainly to a limited number of countries in the developed world [3,27], but there is little published information for developing countries, including Sri Lanka. In addition, although there have been numerous studies of cattle (Bos taurus) in many developed regions of the world [27], there have been few investigations of the molecular epidemiology of cryptosporidiosis and giardiasis in related bovids, such as water buffaloes (Bubalus bubalis) [28,29], which are common domesticated animals in many countries, particularly in Asia.

Although Cryptosporidium and Giardia are known to present clinical problems in humans [30-32] and animals [33-35] in Sri Lanka, there is no detailed epidemiological information on the species and genotypes/assemblages of these parasites present in humans or any other animals. These knowledge gaps relate to the fact that suitable molecular methods have not yet been used previously to identify and characterise such species and genotypes/assemblages in this country. Therefore, in the present study, we conducted the first molecular epidemiological survey in Sri Lanka to establish whether domestic bovids might harbour Cryptosporidium and/or Giardia with zoonotic potential. We used a PCR-based approach employing genetic markers in the small subunit of ribosomal RNA $(S S U), 60 \mathrm{kDa}$ glycoprotein ( gp60) genes for Cryptosporidium and in the triose phosphate isomerase (tpi) gene for Giardia, which have been widely used for the genetic characterization of members of these genera [3,27]; we were particularly focussed on identifying zoonotic genotypes of these protozoa.

\section{Methods}

\section{Sample collection}

Faecal samples were collected rectally from pre-weaned dairy calves (Bos taurus; < 3 months of age) and water buffaloes (Bubalus bubalis; $<6$ months and $\geq 6$ months of age) from seven different farms (designated $A B, N Z$ and DY; BR, HA, NK and MR) in Sri Lanka between August 2012 and February 2013. The three dairy cattle farms (AB, NZ and DY) studied were large, intensive farms, located in the highland wet zone (average $>2000 \mathrm{~mm}$ of annual rainfall and $>900 \mathrm{~m}$ altitude), and maintained Ayrshire, Holstein Friesian and Jersey breeds, respectively. Faecal samples were collected weekly for six weeks from these three dairy farms. At the first visit, faeces were collected from 20 pre-weaned calves (1-12 weeks) from each farm, and individual calves were sampled weekly for 6 weeks, providing a total of 340 samples for molecular testing. In addition, a total of 297 faecal samples were collected once from the two different age groups of water buffalo. The four riverine buffalo herds (BR, $\mathrm{HA}, \mathrm{NK}$ and MR) studied were in two different climatic zones, with an average of 1,750-2,500 and 1,850-5,000 mm of annual rainfall at altitudes of $<300$ and $300-900 \mathrm{~m}$, respectively.

Cattle and buffaloes were born and raised on the farms studied, and fed whole milk (twice a day) until weaning at 3 months of age. Dairy calves were reared in individual pens, whereas buffalo calves were maintained as groups $(n=3-10)$ in pens. Therefore, there was no direct contact between calves and adult cattle or buffaloes. Herd management practices on these dairy and water buffalo farms are typical of large-scale, intensive farms in Sri Lanka.

\section{Isolation of genomic DNA from faecal samples, and PCR amplification}

Genomic DNA was isolated from individual faecal samples using the PowerSoil DNA isolation kit (MoBIO, USA) [29], and then frozen at $-20^{\circ} \mathrm{C}$ until molecular testing. Each genomic DNA sample was tested by PCR for Cryptosporidium DNA employing markers (designated 
$\mathrm{p} S S U$ and $\mathrm{pgp} 60$ ) within the small subunit nuclear ribosomal RNA and $60 \mathrm{kDa}$ glycoprotein genes, and for Giardia DNA using a region (ptpi) within the triose phosphate isomerase gene [29,36]; pgp60 is employed specifically for the detection and assignment of Cryptosporidium species, genotypes or subgenotypes that are infective to humans (cf. [2]). Some genomic DNAs $(n=50)$ were also tested for inhibition of the enzymatic reaction in PCR using a DNAspiking approach [37]. In brief, aliquots $(2 \mu \mathrm{l})$ of individual genomic DNA samples that had been test-negative in PCR were individually spiked with $1 \mathrm{pg}$ of C. parvum DNA and subjected to PCR-based mutation scanning to demonstrate the amplification of a specific product. There was no evidence that samples tested contained constituents inhibitory to PCR.

\section{Mutation scanning-based sequencing and phylogenetic analyses of sequence data}

For pSSU amplicons, single-strand conformation polymorphism (SSCP) analysis [38] was carried out as described previously [39]. For ptpi amplicons, restriction endonuclease fingerprinting was employed, using the enzyme RsaI (Promega) [40-42]. Amplicons representing each banding profile were selected and treated with exonuclease I and shrimp alkaline phosphatase (Fermentas), according to the manufacturer's instructions, and then sequenced in both directions by direct, automated sequencing (BigDye Terminator v.3.1 chemistry, Applied Biosystems, USA), using the same primers employed in secondary PCR. The quality of each sequence was assessed based on the corresponding electropherogram using the program BioEdit [43], and the sequences determined were compared with known reference sequences using the Basic Local Alignment Search Tool (BLAST; http://www. ncbi.nlm.nih.gov/BLAST). Phylogenetic analysis of sequence data was performed using the Bayesian inference (BI) tree building method in MrBayes 3.1.2 [44,45]. Posterior probabilities ( $\mathrm{pp}$ ) were calculated via 2,000,000 generations, utilizing four simultaneous tree-building chains, with every 100th tree being saved. At this point, the standard deviation of split frequencies was $<0.01$, and the potential scale reduction factor (PSRF) approached one. A 50\% majority rule consensus tree for each analysis was constructed based on the final $75 \%$ of trees generated by BI.

Phylogenetic analysis was conducted to assess the relationships of the sequences from the present study to those available from public databases for species or genotypes of Cryptosporidium, and published in the peerreviewed literature. In brief, species were determined based on $100 \%$ sequence homology to known species of Cryptosporidium. Phylogenetic analysis was used to provide unequivocal support for the classification of species and genotypes of Cryptosporidium; new genotypes were designated using sequential numbers, according to a previous study [29]. In addition, statistical analysis of proportional difference was performed using the Fisher's exact test [46].

\section{Results}

\section{Cryptosporidium species/genotypes in cattle}

Although pgp60 was not amplified from any of the 340 genomic DNA samples tested, the pSSU region was amplified from 211 (62.1\%) of them. SSCP-based analysis of all amplicons revealed eight unique banding profiles. In total, 60 amplicons representing these eight profiles were sequenced (5-10 per profile). No sequence variation was detected among all sequences representing each SSCP profile, such that, ultimately, eight unique pSSU sequences (GenBank accession nos. KF891285KF891292) were defined. These eight sequences differed by $72-99 \%$ upon pairwise comparison. Phylogenetic analysis (Figure 1) of these eight as well as 70 reference sequences (Additional file 1) included for comparative purposes revealed C. bovis (accession no. KF891286), C. ryanae (KF891285) and six new records (genotypes) that were genetically similar (72-99\%) but not identical to $C$. andersoni $(\mathrm{n}=1$; accession no. KF891291), C. bovis $(\mathrm{n}=$ 1; KF891290), C. ryanae ( $\mathrm{n}=3$; KF891287-KF891289) or C. suis $(\mathrm{n}=1$; KF891292), respectively (see Additional files 2 and 3). In the epidemiological context (Table 1), C. bovis and C. ryanae were detected in $5.6 \%$ and $7.4 \%$ of all samples only from farm $A B$, respectively, and the six new Cryptosporidium sequence types (accession nos. KF891287-KF891292) were detected in $0.3-27.6 \%$ of samples from farms AB, DY and/or NZ (Table 1).

\section{Cryptosporidium species/genotypes in water buffaloes}

Although pgp60 was not amplified from any of the 297 genomic DNA samples tested, the pSSU region was amplified from 29 (9.8\%) of them. SSCP-based analysis of amplicons revealed three unique banding profiles. In total, nine amplicons representing these three profiles were sequenced. No sequence variation was detected among all three sequences representing each SSCP profile, such that, finally, three unique $\mathrm{p} S S U$ sequences (GenBank accession nos. KF891292-KF891294) were defined. These three new sequence types differed by $84-97 \%$ upon pairwise comparison. Based on the phylogenetic analysis, two sequence types (accession nos. KF891293 and KF891294) were genetically most similar but not identical to Cryptosporidium genotypes reported previously from water buffaloes (see Figure 1). The other sequence type defined was the same as the $\mathrm{p} S S U$ sequence of Cryptosporidium with accession no. KF891292 recorded in cattle in the present study (see section on Cryptosporidium species/genotypes in cattle). In the epidemiological context (Table 1), the Cryptosporidium 


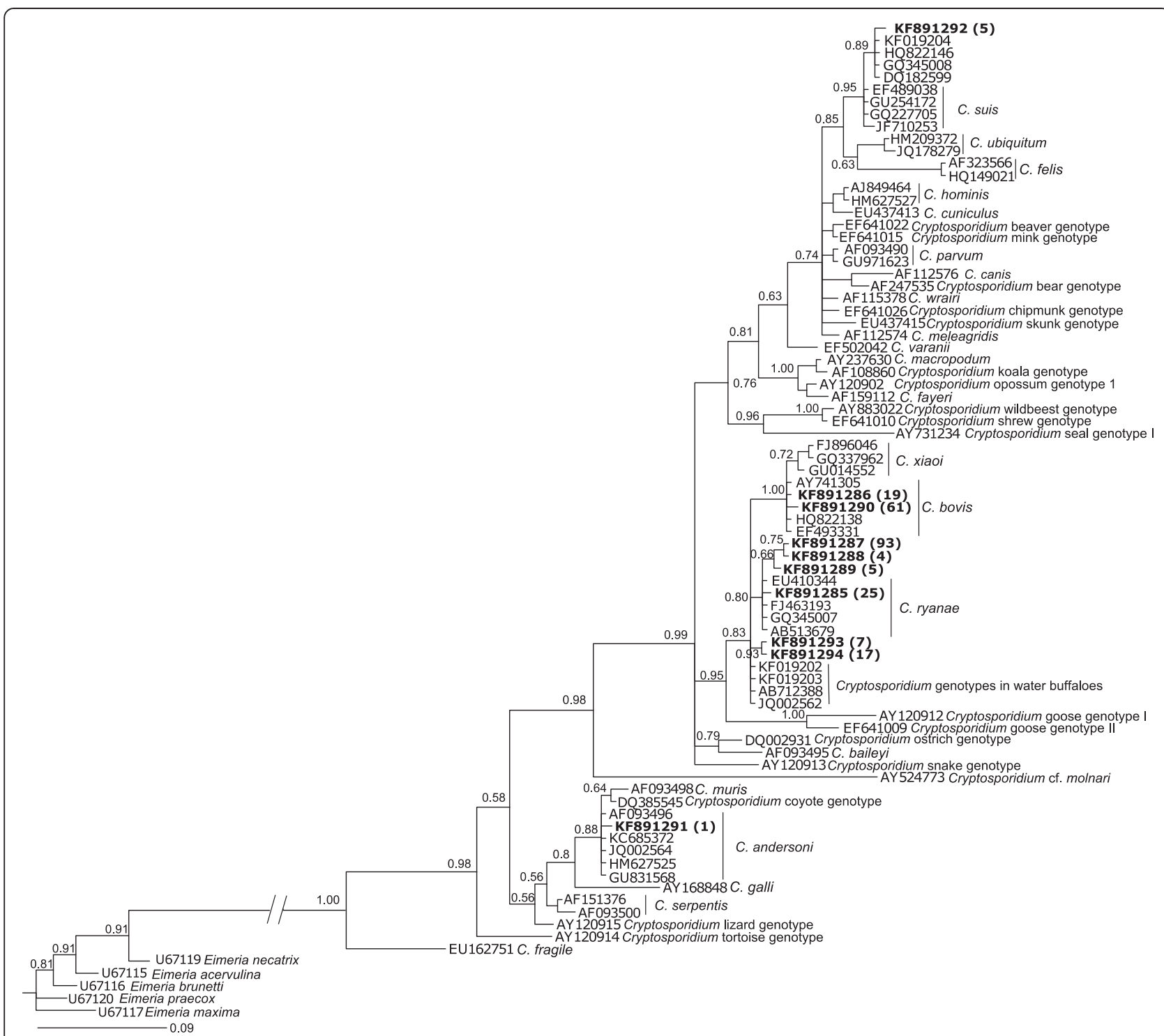

Figure 1 Phylogenetic analysis of pSSU sequence data for Cryptosporidium using Bayesian inference (BI) analysis. The ten distinct pSSU sequences determined in the present study and 36 reference sequences representing Cryptosporidium (accession nos. listed in Additional file 1) were included in the analysis. Eimeria necatrix, E. acervulina, E. brunetti, E. praecox and E. maxima sequences were used as outgroups. Accession numbers of publicly available sequences are indicated at the ends of the branches. Accession numbers linked to sequences determined in the present study are in bold-type; the numbers of samples with particular sequence types are in parentheses. Posterior probabilities (pp) for major nodes are indicated.

Table 1 Cryptosporidium species/genotypes and Giardia duodenalis assemblages detected in faecal samples from dairy cattle from three farms in Sri Lanka

\begin{tabular}{|c|c|c|c|c|c|c|c|c|c|c|c|}
\hline \multirow[t]{2}{*}{ Farm } & \multirow[t]{2}{*}{ Total } & \multicolumn{8}{|c|}{ Cryptosporidium species or genotypes* } & \multicolumn{2}{|c|}{ Giardia duodenalis assemblages* } \\
\hline & & $\begin{array}{l}\text { C. ryanae } \\
\text { (KF891285) }\end{array}$ & $\begin{array}{c}\text { C. bovis } \\
\text { (KF891286) }\end{array}$ & $\begin{array}{r}\text { Genotype } 4 \\
\text { (KF891287) }\end{array}$ & $\begin{array}{l}\text { Genotype } 5 \\
\text { (KF891290) }\end{array}$ & $\begin{array}{l}\text { Genotype } 6 \\
\text { (KF891288) }\end{array}$ & $\begin{array}{l}\text { Genotype } 7 \\
\text { (KF891289) }\end{array}$ & $\begin{array}{l}\text { Genotype } 8 \\
\text { (KF891291) }\end{array}$ & $\begin{array}{l}\text { Genotype } 9 \\
\text { (KF891292) }\end{array}$ & $\begin{array}{c}\text { Assemblage A } \\
\text { (KF891295) }\end{array}$ & $\begin{array}{c}\text { Assemblage E } \\
\text { (KF891296- } \\
\text { KF891310) }\end{array}$ \\
\hline$A B$ & 117 & 25 & 19 & 22 & 9 & 1 & 0 & 0 & 0 & 0 & 60 \\
\hline $\mathrm{NZ}$ & 120 & 0 & 0 & 31 & 38 & 0 & 0 & 0 & 2 & 0 & 39 \\
\hline DY & 103 & 0 & 0 & 41 & 14 & 3 & 5 & 1 & 0 & 4 & 38 \\
\hline Total & 340 & 25 & 19 & 94 & 61 & 4 & 5 & 1 & 2 & 4 & 137 \\
\hline
\end{tabular}

*GenBank accession nos. are given in round parentheses. 
Table 2 Cryptosporidium genotypes and Giardia duodenalis assemblage E detected in faecal samples from buffaloes from four farms in Sri Lanka

\begin{tabular}{lccccc}
\hline Farm & Total & \multicolumn{3}{c}{ Cryptosporidium genotypes* } & $\begin{array}{c}\text { Giardia duodenalis } \\
\text { assemblage E* }\end{array}$ \\
\cline { 3 - 6 } & & $\begin{array}{c}\text { Genotype } \\
\text { (KF891292) }\end{array}$ & $\begin{array}{c}\text { Genotype 10 } \\
\text { (KF891293) }\end{array}$ & $\begin{array}{c}\text { Genotype 11 } \\
\text { (KF891294) }\end{array}$ & $\begin{array}{c}\text { (KF891311 and KF891312) } \\
\text { and }\end{array}$ \\
\hline HA & 51 & 0 & 0 & 9 & 0 \\
BR & 58 & 0 & 4 & 0 & 0 \\
NK & 82 & 0 & 2 & 0 & 1 \\
MR & 106 & 5 & 1 & 8 & 2 \\
Total & 297 & 5 & 7 & 17 & 2 \\
\hline
\end{tabular}

*GenBank accession nos. are given within round parentheses.

sequence types with accession nos. KF891293, KF891294 and KF891292 were detected in 2.4\% (farms BR, NK and MR), 5.7\% (farms HA and MR) and 1.7\% (farm MR) of the 297 samples tested, respectively.

Cryptosporidium was detected on all four water buffalo farms (Table 2). Samples test-positive for Cryptosporidium were detected in 25 (8.4\%) and four (1.3\%) of 297 samples from animals in the categories of $<6$ months and $\geq 6$ months of age, respectively (Table 3 ). The lowest (2.4\%) and highest (17.6\%) percentages of samples testpositive for Cryptosporidium were detected on farms NK and HA, respectively, but there was no significant difference in numbers of test-positive samples between the two different climatic regions in which samples were collected. The total number of calves ( $<6$ months) that were test-positive for Cryptosporidium was significantly lower for water buffaloes than for cattle in the study population $(P<0.001)$.

\section{Detection of Giardia duodenalis in cattle}

All 340 faecal genomic DNA samples were subjected to genetic analysis for Giardia. The ptpi locus was amplified from 141 (41.5\%) of these samples. SSCP analysis of all 141 amplicons displayed 16 distinct profiles. The direct sequencing of 60 amplicons representing all 16 profiles defined 16 distinct sequence types (GenBank accession nos. KF891295-KF891310). These 16 sequences differed by $86-99 \%$ upon pairwise comparison. All sequences ( $\sim 530 \mathrm{bp})$ representing the 16 profiles were compared with publicly available sequences. One of the 16 sequences was identical to the reference sequence (accession number L02120) for G. duodenalis assemblage A. The 15 other sequences were identified as G. duodenalis assemblage E (Table 4). Three of the 15 sequences were identical to $G$. duodenalis assemblage $\mathrm{E}$ sequences with accession nos. JN162349, JN162348 and EF654688, respectively. Twelve other sequences were $99 \%$ similar to G. duodenalis assemblage E sequences with GenBank accession nos. JN162349 $(\mathrm{n}=5), \mathrm{JN} 162348(\mathrm{n}=2), \mathrm{JN} 162347(\mathrm{n}=3)$ and GQ444455 $(\mathrm{n}=2)$. A comprehensive phylogenetic analysis (Figure 2) supported their classification; the 15 and one sequences determined in this study clustered, with strong nodal support $(\mathrm{pp}=1.00)$, with $\mathrm{G}$. duodenalis assemblages $\mathrm{E}$ and A, respectively (Figure 2).

These results were then put into an epidemiological context. Giardia was detected molecularly in 141 (22.1\%) samples originating from all three cattle farms. Assemblages A and E were identified in four and 137 of these samples. The highest percentage of test-positive samples was detected in cattle on farm $\mathrm{AB}$ (51.3\%), followed by farms DY (40.8\%) and NZ (32.5\%). Each cattle farm had 19 calves that were test-positive for Giardia at some stage during the sampling period. Mixed infections of Cryptosporidium and Giardia were detected in 98 (28.8\%) of 340 samples. Of 60 cattle from all three farms, 57 had mixed infections of Cryptosporidium and Giardia at least once during the 6-week sampling period. The total number of calves ( $<6$ months) that were test-positive for Giardia was significantly higher for cattle than for water buffaloes $(\mathrm{P}<0.001)$.

Table 3 Cryptosporidium genotypes and Giardia duodenalis assemblage E detected in faecal samples collected from two different age groups of water buffaloes in Sri Lanka

\begin{tabular}{|c|c|c|c|c|c|}
\hline \multirow[t]{2}{*}{ Age group } & \multirow[t]{2}{*}{ Total } & \multicolumn{3}{|c|}{ Cryptosporidium genotypes* } & \multirow{2}{*}{$\begin{array}{l}\text { Giardia duodenalis assemblage E* } \\
\text { (KF891311 and KF891312) }\end{array}$} \\
\hline & & $\begin{array}{r}\text { Genotype } 9 \\
\text { (KF891292) }\end{array}$ & $\begin{array}{c}\text { Genotype } 10 \\
\text { (KF891293) }\end{array}$ & $\begin{array}{c}\text { Genotype } 11 \\
\text { (KF891294) }\end{array}$ & \\
\hline$<6$ months & 108 & 5 & 5 & 15 & 1 \\
\hline$\geq 6$ months & 189 & 0 & 2 & 2 & 1 \\
\hline Total & 297 & 5 & 7 & 17 & 2 \\
\hline
\end{tabular}

*GenBank accession nos. are given in round parentheses. 
Table 4 Fifteen different ptpi sequences representing assemblage E of Giardia duodenalis detected in cattle and buffaloes in Sri Lanka

\begin{tabular}{llll}
\hline Farm & Host & Numbers of samples (accession nos.)* & Subtotal \\
\hline AB & Cattle (Bos taurus) & 47 (KF891296), 3 (KF8912967), 3 (KF891298), 2 (KF891299), 2 (KF891300), 2 (KF891301), 1 (KF891302) & 60 \\
NZ & Cattle & 20 (KF891296), 10 (KF891297), 3 (KF891304), 2 (KF891303), 1 (KF891305), 1 (KF891306), 1 (KF891307), 1 (KF891298) & 39 \\
DY & Cattle & 29 (KF891298), 4 (KF891296), 2 (KF891308), 1 (KF891301), 1 (KF891309), 1 (KF891310) & 38 \\
HA & Water buffalo (Bubalus bubalis) & 1 (KF891311) & 1 \\
MR & Water buffalo & 1 (KF891312) & 1 \\
BR & Water buffalo & 0 & 0 \\
NK & Water buffalo & 0 & 0 \\
& & Total & 139 \\
\hline
\end{tabular}

*GenBank accession nos. are indicated in round parentheses.

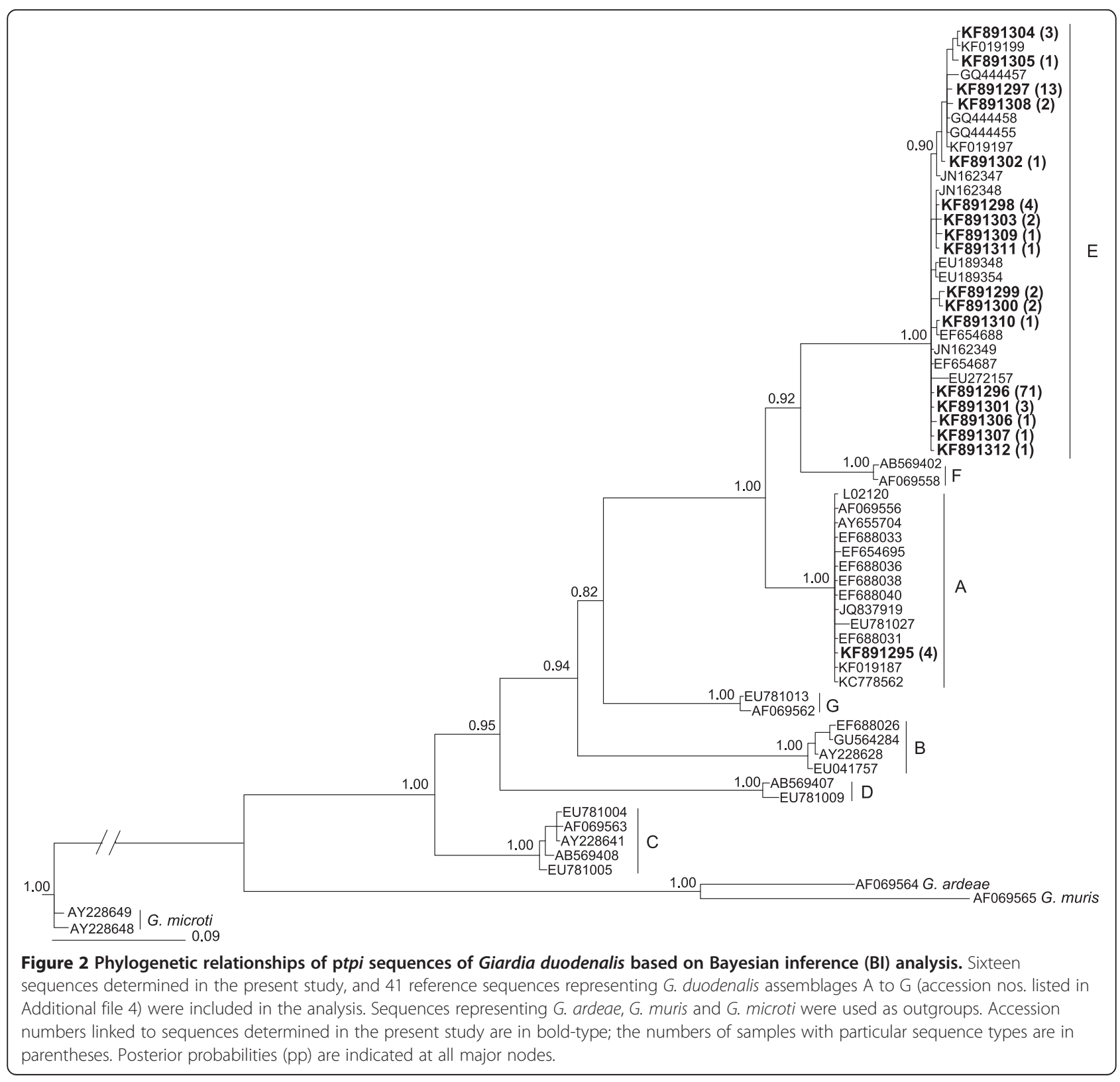




\section{Detection of Giardia duodenalis in water buffalo}

All 297 faecal genomic DNA samples were subjected to genetic analysis for Giardia. The ptpi locus was amplified from two $(0.7 \%)$ of these samples; the two samples were from water buffaloes of $<1$ year of age (farms HA and MR: $\geq 6$ months of age on both farms). The two amplicons were sequenced directly and compared with publicly available sequences. The sequences (GenBank accession nos. KF891311 and KF891312) were the same as two reference sequences (accession nos. JN162348 and JN162349) representing G. duodenalis assemblage E (Additional file 4). The two samples test-positive for Giardia also both contained a Cryptosporidium sequence type with accession no. KF891294.

\section{Discussion}

This study genetically characterised, for the first time, Cryptosporidium and Giardia from Bos taurus and Bubalus bubalis in Sri Lanka. Cryptosporidium was identified in $62.1 \%$ and $9.8 \%$ of 340 samples, and Giardia in $41.5 \%$ and $0.7 \%$ of 279 samples from these two respective bovid hosts. Overall, two Cryptosporidium species (C. bovis and C. ryanae) and eight new genotypes were defined based on their pSSU sequence $(\mathrm{n}=5$, accession nos. KF891287-KF891291 in cattle; $n=2$, KF891293 and KF891294 in water buffalo; and $\mathrm{n}=1$, KF891292 in both cattle and buffalo). C. bovis and C. ryanae were detected in calves of 10 and 19 days of age, respectively, time points which are relatively consistent with the pre-patent periods reported for these species of Cryptosporidium [47]. Although both C. bovis and C. ryanae (previously called Cryptosporidium "deer-like genotype") have been widely reported in calves from different countries throughout the world $[48,49]$, the eight genotypes characterised here are novel. Consistent with the findings for pSSU, no zoonotic species or genotypes of Cryptosporidium were detected using pgp60, in the absence of any evidence of PCR inhibition.

The first new Cryptosporidium genotype represented by accession no. KF891287, which is distinct in pSSU sequence by one nucleotide substitution $(\mathrm{G}->\mathrm{C}$ at alignment position 220; Additional file 3) from C. ryanae (accession no. EU410344), was most commonly detected (44.5\%) amongst the 211 Cryptosporidium test-positive samples from cattle. This genotype was detected at least once on all three cattle farms studied and at least once during the 6-week sampling period. The second most frequent (28.9\%), new Cryptosporidium genotype pertaining to accession no. KF891290 differed in sequence by one nucleotide substitution ( $\mathrm{G}->\mathrm{C}$ at position 220; Additional file 3) from C. bovis (AY741305) and was also detected on all three cattle farms examined.

The third and fourth new Cryptosporidium genotypes (accession nos. KF891288 and KF891289), which both differed by two nucleotides (insertion of $\mathrm{T}$ or $\mathrm{A}$ at alignment positions 73 and 74, and a $\mathrm{G}->\mathrm{C}$ at position 220; Additional file 3) from C. ryanae, were each recorded in four and five samples, respectively, from farms $A B$ and DY. These two genotypes differed by only one nucleotide (G->C) from previously reported C. ryanae variants (accession nos. KC778534 and KC778535; [50]).

The fifth new genotype (accession no. KF891291), which differed in sequence by one nucleotide from $C$. andersoni, was identified in one sample. Phylogenetic analysis (Figure 1) revealed that the sequence representing this genotype formed a monophyletic group, with five reference sequences representing $C$. andersoni (pp $=0.88)$. Although $C$. andersoni occurs in adult cattle, it has been found occasionally in pre-weaned calves [51-55]. The sixth new genotype (accession no. KF891292) was identified in two faecal samples from one calf on one farm (NZ) and five samples isolated from water buffaloes from another farm (MR). This genotype is one nucleotide different from the pSSU sequence of a new Cryptosporidium genotype described previously in cattle in Australia (accession no. KC778530; [50]), Denmark (accession no. DQ182599; [56]), India (accession no. GQ345008; [57]) and the UK (accession no. HQ822134; [58]), and also in water buffaloes in Australia (accession no. KF019204; [29]). Published sequence data for the heat shock protein 70 ( $h s p 70)$ and actin genes also supported the validity of this new genotype [58]. Therefore, this genotype might represent a new species, but it remains to be described.

The seventh and eighth new genotypes (represented by accession nos. KF891293 and KF891294) recorded from water buffaloes differed in sequence by a single point mutation (G- > C at position 220; Additional file 3) from genotypes 1 and 2 (accession nos. KF019202 and KF019203) described recently [29] in water buffaloes in Australia, and they were genetically most similar to those represented by accession nos. KF019202, KF019203, AB712388 and JQ002562 $[29,59,60]$ in the phylogenetic analysis. These results indicate that these two novel genotypes of Cryptosporidium are buffalo-affiliated, but these genotypes are clearly different from C. ryanae from cattle [47].

Most samples (86.2\% of 29) test-positive for Cryptosporidium in water buffaloes were detected in calves of $<6$ months of age. This result is consistent with previous studies $[29,61,62]$, in which the occurrence of Cryptosporidium infection has been reported to be higher in water buffaloes of $<6$ months than in those of $\geq 6$ months of age. A novel genotype represented by accession no. KF891294 was most frequently detected (58.6\%) among Cryptosporidium test-positive samples from water buffaloes. It was also detected more frequently in samples collected from calves of $<6$ months of age group than those of $\geq 6$ months age group. All of the eight novel genotypes identified here in cattle and buffaloes from Sri Lanka had a unique single-nucleotide $(\mathrm{G}<->\mathrm{C})$ substitution in $\mathrm{pSSU}$ 
(Additional file 3) and appear to be autochthonous to this country.

Surprisingly, C. parvum, the most commonly reported zoonotic species of Cryptosporidium recognised in cattle throughout the world $[2,15,48]$, was not detected in the present study in any of the samples collected from calves of 1 week to 3 months of age using a repeated sampling strategy (every week for six weeks). According to epidemiological studies conducted in many countries [16,52,55,63-67], C. parvum is most commonly detected in calves of $<3$ months of age. According to a longitudinal survey conducted by Santín and colleagues [55], C. parvum was detected in $85 \%$ of 503 pre-weaned calves, whereas only $1 \%$ was associated with post-weaned calves. For this reason, pre-weaned calves are recognised as the major reservoir for human cryptosporidiosis [2]. However, some recent epidemiological studies have reported an abundance of C. bovis infection and a limited presence of C. parvum in calves of 1-60 days of age in China [23,68,69], India [68] Nigeria [70] and Sweden [71]. Taken together, the present findings suggest that calves of this age group are not reservoirs for human $C$. parvum infection in the geographical regions studied here in Sri Lanka. A likely explanation for this unexpected result might relate to sound husbandry practices on farms in Sri Lanka. The three cattle farms studied were well-managed, intensive farms, and pre-weaned calves were kept and fed/ watered in individual, elevated wooden calf pens with slatted floors.

G. duodenalis assemblage A was detected in only four samples from calves on one dairy farm (DY), whereas $97 \%$ of samples test-positive for Giardia in cattle related to $G$. duodenalis assemblage E. This result is consistent with the previous studies [50,72-76] reporting that $80-100 \%$ of the G. duodenalis isolated from cattle are in assemblage $E$. This assemblage was detected in calves on all three dairy farms and, at least once, in individual calves during the 6-week period of sampling. The two samples test-positive for Giardia in water buffaloes on farms $\mathrm{HA}$ and MR contained G. duodenalis assemblage E, although Giardia was not detected on the other two farms. Previous molecular studies conducted in Australia [29] and Italy [28] have also reported $G$. duodenalis assemblage $\mathrm{E}$ in water buffaloes. These findings support the proposal that cattle and water buffaloes in the geographical areas studied in Sri Lanka are not significant reservoirs for human infection with Giardia.

Both Cryptosporidium and Giardia were detected concurrently in $28.8 \%$ of 340 samples from cattle, which is in accordance with previous studies of cattle [77-79]. For each genus, the numbers of test-positive samples were higher in cattle than in water buffaloes, which seems to be consistent with a prevalence of up to $100 \%$ recorded in studies of dairy calves [22] compared with 9.5-38.3\% in water buffalo $[28,29,61,80-82]$.

\section{Conclusions}

Results of the present study suggest that the epidemiology of bovine cryptosporidiosis and giardiasis in Sri Lanka is distinct from those of other parts of the world. Unique nucleotide substitutions in the pSSU region appear to be specific to Sri Lanka. Expanded studies of domestic and wild bovids in various regions in Sri Lanka are required to test this proposal. The apparent absence of C. parvum from cattle and buffaloes and the low occurrence of G. duodenalis assemblage $\mathrm{A}$ in cattle suggest that bovids in the regions studied here have limited significance as reservoirs for human infections. Future work should be focused on largescale studies to investigate the molecular epidemiology of cryptosporidiosis and giardiasis in a wide range of animals in Sri Lanka and in neighbouring countries in South Asia.

\section{Additional files}

\begin{abstract}
Additional file 1: Summary of salient information (Cryptosporidium species/genotypes, host/environmental source, country, GenBank accession nos. of sequences and associated references) pertaining to the SSU sequences used in the phylogenetic analysis of pSSU data (see Figure 1).
\end{abstract}

Additional file 2: Pairwise comparison of nucleotide sequence differences in the small subunit of nuclear ribosomal RNA (pSSU) among Cryptosporidium species or genotypes representing reference sequences (GenBank accession nos. EU410344, AY741305, EU245042, EF489038, EU331243 and AB712384) and those from bovids studied herein (bold-type).

Additional file 3: An alignment of known reference sequences representing a part of the small subunit of nuclear ribosomal RNA (pSSU) of Cryptosporidium species or genotypes (GenBank accession nos. EU410344, AY741305, EU245042, EF489038, EU331243 and AB712384) with homologous sequences derived from Cryptosporidium from bovids in the present study. A dot denotes a nucleotide that is identical to that in the top sequence; a dash represents a gap.

Additional file 4: Summary of salient information (Giardia species/ assemblages, host origins, country, accession nos. of sequences and associated references) pertaining to the tpi sequences used in the phylogenetic analysis of ptpi data (see Figure 2).

\section{Competing interests}

The authors declare that they have no competing interests.

\section{Authors' contributions}

HA carried out molecular laboratory work, data analysis, interpretation and drafting of the manuscript. KU collected samples. AVK assisted with the phylogenetic analyses. HA, RBG and ARJ wrote the manuscript with critical input from RPVJR and other authors. RBG and ARJ conceived the project and attracted the funding. All authors read and approved the final version of the manuscript.

\section{Acknowledgements}

Funding support from the Australian Research Council (ARC), Melbourne Water Corporation (MWC), National Health and Medical Research Council (NHMRC) and the Alexander von Humboldt Foundation is gratefully acknowledged. 


\section{Author details}

${ }^{1}$ Faculty of Veterinary Science, The University of Melbourne, Parkville, Victoria, Australia. ${ }^{2}$ Department of Veterinary Pathobiology, Faculty of Veterinary Medicine and Animal Science, University of Peradeniya, Peradeniya, Sri Lanka. ${ }^{3}$ Melbourne Water Corporation, Victoria, Australia.

Received: 20 January 2014 Accepted: 5 February 2014

Published: 21 February 2014

\section{References}

1. Ryan UM, Cacciò SM: Zoonotic potential of Giardia. Int J Parasitol 2013, 43(12-13):943-956.

2. Jex AR, Chalmers RM, Smith HV, Widmer G, McDonald V, Gasser RB: Cryptosporidiosis. In Oxford Textbook of Zoonoses. Edited by Palmer SR, Soulsby L, Torgerson PR, Brown DWG. New York: Oxford University Press Inc:; 2011 (Chapter 46).

3. Feng Y, Xiao L: Zoonotic potential and molecular epidemiology of Giardia species and giardiasis. Clin Microbiol Rev 2011, 24(1):110-140.

4. Snelling WJ, Xiao L, Ortega-Pierres G, Lowery CJ, Moore JE, Rao JR, Smyth S, Millar BC, Rooney PJ, Matsuda M, Kenny F, Xu J, Dooley JS: Cryptosporidiosis in developing countries. J Infect Dev Ctries 2007, 1(3):242-256.

5. Chalmers RM, Davies AP: Minireview: clinical cryptosporidiosis. Exp Parasitol 2010, 124(1):138-146

6. Hunter PR, Nichols G: Epidemiology and clinical features of Cryptosporidium infection in immunocompromised patients. Clin Microbiol Rev 2002, 15(1):145-154.

7. Petri WA, Miller M, Binder HJ, Levine MM, Dillingham R, Guerrant RL: Enteric infections, diarrhea, and their impact on function and development. J Clin Invest 2008, 118(4):1277-1290.

8. Tian L, Chen J, Wang T, Cheng G, Steinmann P, Wang F, Cai Y, Yin X, Guo J, Zhou L, Zhou X: Co-infection of HIV and intestinal parasites in rural area of China. Parasit Vectors 2012, 5(1):36-42.

9. Robertson B, Sinclair MI, Forbes AB, Veitch M, Kirk M, Cunliffe D, Willis J, Fairley CK: Case-control studies of sporadic cryptosporidiosis in Melbourne and Adelaide, Australia. Epidemiol Infect 2002, 128(3):419-431.

10. Yoder JS, Beach MJ: Cryptosporidium surveillance and risk factors in the United States. Exp Parasitol 2010, 124(1):31-39.

11. Abu-Madi MA, Behnke JM, Ismail A, Al-Olaqi N, Al-Zaher K, El-lbrahim R: Comparison of intestinal parasitic infection in newly arrived and resident workers in Qatar. Parasit Vectors 2011, 4:211-211.

12. Júlio C, Vilares A, Oleastro M, Ferreira I, Gomes S, Monteiro L, Nunes B, Tenreiro R, Ângelo H: Prevalence and risk factors for Giardia duodenalis infection among children: A case study in Portugal. Parasit Vectors 2012, 5(1):22-29.

13. Xiao L, Fayer R: Molecular characterisation of species and genotypes of Cryptosporidium and Giardia and assessment of zoonotic transmission. Int J Parasitol 2008, 38(11):1239-1255.

14. Thompson RCA: Giardia infections. In Oxford Textbook of Zoonoses. Edited by Palmer SR, Soulsby L, Torgerson PR, Brown DWG. New York: Oxford University Press Inc; 2011 (Chapter 45).

15. Xiao L, Feng Y: Zoonotic cryptosporidiosis. FEMS Immunol Med Microbiol 2008, 52:309-323.

16. Ng JSY, Eastwood K, Walker B, Durrheim DN, Massey PD, Porigneaux P, Kemp R, McKinnon B, Laurie K, Miller D, Bramley E, Ryan UM: Evidence of Cryptosporidium transmission between cattle and humans in northern New South Wales. Exp Parasitol 2012, 130(4):437-441.

17. Ashbolt RH, Coleman DJ, Misrachi A, Conti JM, Kirk MD: An outbreak of cryptosporidiosis associated with an animal nursery at a regional fair. Commun Dis Intell 2003, 27(2):244-249.

18. Hunter PR, Hughes S, Woodhouse S, Syed Q, Verlander NQ, Chalmers RM Morgan K, Nichols G, Beeching N, Osborn K: Sporadic cryptosporidiosis case-control study with genotyping. Emerg Infect Dis 2004, 10(7):1241-1249.

19. Roy SL, DeLong SM, Stenzel SA, Shiferaw B, Roberts JM, Khalakdina A, Marcus R, Segler SD, Shah DD, Thomas S, Vugia DJ, Zansky SM, Dietz V, Beach MJ: Risk factors for sporadic cryptosporidiosis among immunocompetent persons in the United States from 1999 to 2001. J Clin Microbiol 2004, 42(7):2944-2951.

20. Kiang KM, Scheftel JM, Leano FT, Taylor CM, Belle-Isle PA, Cebelinski EA, Danila R, Smith KE: Recurrent outbreaks of cryptosporidiosis associated with calves among students at an educational farm programme, Minnesota, 2003. Epidemiol Infect 2006, 134(4):878-886.
21. Hunter PR, Thompson RCA: The zoonotic transmission of Giardia and Cryptosporidium. Int J Parasitol 2005, 35(11-12):1181-1190.

22. Trout JM, Santín M: Livestock. In Cryptosporidium and Cryptosporidiosis. 2nd edition. Edited by Fayer R, Xiao L. Boca Raton, Fl: CRC Press; 2008:451-483.

23. Wang R, Wang H, Sun Y, Zhang L, Jian F, Qi M, Ning C, Xiao L: Characteristics of Cryptosporidium transmission in preweaned dairy cattle in Henan, China. J Clin Microbiol 2011, 49(3):1077-1082.

24. Budu-Amoako E, Greenwood SJ, Dixon BR, Barkema HW, McClure JT: Foodborne illness associated with Cryptosporidium and Giardia from livestock. J Food Prot 2011, 74(11):1944-1955.

25. Thompson RCA: The zoonotic significance and molecular epidemiology of Giardia and giardiasis. Vet Parasitol 2004, 126(1-2):15-35.

26. Geurden T, Vercruysse J, Claerebout E: Is Giardia a significant pathogen in production animals? Exp Parasitol 2010, 124(1):98-106.

27. Jex AR, Gasser RB: Genetic richness and diversity in Cryptosporidium hominis and C. parvum reveals major knowledge gaps and a need for the application of "next generation" technologies. Biotechnol Adv 2010 28:17-26.

28. Cacciò SM, Rinaldi L, Cringoli G, Condoleo R, Pozio E: Molecular identification of Cryptosporidium parvum and Giardia duodenalis in the Italian water buffalo (Bubalus bubalis). Vet Parasitol 2007, 150(1-2):146-149.

29. Abeywardena H, Jex AR, von Samson-Himmelstjerna G, Haydon SR, Stevens MA, Gasser RB: First molecular characterisation of Cryptosporidium and Giardia from Bubalus bubalis (water buffalo) in Victoria, Australia. Infect Genet Evol 2013, 20:96-102.

30. Perera J: Cryptosporidium associated childhood diarrhoea in Sri Lanka - a preliminary study. Ceylon Med J 1988, 33(3):101-104.

31. Perera J, Lucas GN: Cryptosporidiosis-oocyst shedding and infection in household contacts. Ceylon Med J 1990, 35(1):11-14.

32. Perera J, Jayawardena I, Mendis L, Abeyratne K: Intestinal parasites and diarrhoea in a children's hospital in Sri Lanka. Ceylon J Med 1999, 42:7-12.

33. Bahirathan M, Weilgama DJ, Wijesundera MKDS: Identification of three species of Eimeria and oocysts of Cryptosporidium from calves in Sri Lanka. Sri Lanka Vet J 1987, 35:13-18.

34. Noordeen F, Rajapakse RPVJ, Faizal AC, Horadagoda NU, Arulkanthan A: Prevalence of Cryptosporidium infection in goats in selected locations in three agroclimatic zones of Sri Lanka. Vet Parasitol 2000, 93(2):95-101.

35. Ekanayake DK, Arulkanthan A, Horadagoda NU, Sanjeevani GK, Kieft R, Gunatilake S, Dittus WP: Prevalence of Cryptosporidium and other enteric parasites among wild non-human primates in Polonnaruwa, Sri Lanka. Am J Trop Med Hyg 2006, 74(2):322-329.

36. Abeywardena H, Jex AR, Nolan MJ, Haydon SR, Stevens MA, McAnulty RW, Gasser RB: Genetic characterisation of Cryptosporidium and Giardia from dairy calves: Discovery of species/genotypes consistent with those found in humans. Infect Genet Evol 2012, 12:1984-1993.

37. Jiang J, Alderisio KA, Singh A, Xiao L: Development of procedures for direct extraction of Cryptosporidium DNA from water concentrates and for relief of PCR inhibitors. Appl Environ Microbiol 2005, 71(3):1135-1141.

38. Gasser RB, Hu M, Chilton NB, Campbell BE, Jex AR, Otranto D, Cafarchia C, Beveridge I, Zhu XQ: Single-strand conformation polymorphism (SSCP) for the analysis of genetic variation. Nat Protoc 2006, 1(6):3121-3128.

39. Jex AR, Ryan UM, Ng J, Campbell BE, Xiao L, Stevens M, Gasser RB: Specific and genotypic identification of Cryptosporidium from a broad range of host species by nonisotopic SSCP analysis of nuclear ribosomal DNA. Electrophoresis 2007, 28(16):2818-2825

40. Nolan MJ, Jex AR, Pangasa A, Young ND, Campbell AJ, Stevens M, Gasser RB: Analysis of nucleotide variation within the triose-phosphate isomerase gene of Giardia duodenalis from sheep and its zoonotic implications. Electrophoresis 2010, 31(2):287-298.

41. Orita M, Iwahana H, Kanazawa H, Hayashi K, Sekiya T: Detection of polymorphisms of human DNA by gel electrophoresis as single-strand conformation polymorphisms. Proc Natl Acad Sci U S A 1989, 86(8):2766-2770.

42. Zhu XQ, Gasser RB: Single-strand conformation polymorphism (SSCP)based mutation scanning approaches to fingerprint sequence variation in ribosomal DNA of ascaridoid nematodes. Electrophoresis 1998, 19(8-9):1366-1373.

43. Hall TA: BioEdit: a user-friendly biological sequence alignment editor and analysis program for Windows 95/98/NT. Nucleic Acids Symp Ser 1999, 41:95-98.

44. Ronquist F, Huelsenbeck JP: MrBayes 3: Bayesian phylogenetic inference under mixed models. Bioinformatics 2003, 19(12):1572-1574. 
45. Huelsenbeck JP, Ronquist F: MRBAYES: Bayesian inference of phylogenetic trees. Bioinformatics 2001, 17(8):754-755.

46. Petrie A, Watson PF: Statistics for veterinary and animal science. 3rd edition. Oxford: Blackwell Publishing; 2013.

47. Fayer R, Santín M, Trout JM: Cryptosporidium ryanae n. sp. (Apicomplexa: Cryptosporidiidae) in cattle (Bos taurus). Vet Parasitol 2008, 156:191-198.

48. Xiao L: Molecular epidemiology of cryptosporidiosis: an update. Exp Parasitol 2010, 124(1):80-89.

49. Santín M: Clinical and subclinical infections with Cryptosporidium in animals. N Z Vet J 2012, 61(1):1-10

50. Abeywardena H, Jex AR, Firestone SM, McPhee S, Driessen N, Koehler AV, Haydon SR, von Samson-Himmelstierna G, Stevens MA, Gasser RB: Assessing calves as carriers of Cryptosporidium and Giardia with zoonotic potential on dairy and beef farms within a water catchment area by mutation scanning. Electrophoresis 2013, 34(15):2259-2267.

51. Kváč M, Hromadová N, Květoňová D, Rost M, Sak B: Molecular characterization of Cryptosporidium spp. in pre-weaned dairy calves in the Czech Republic: absence of $C$. ryanae and management-associated distribution of C. andersoni, C. bovis and C. parvum subtypes. Vet Parasitol 2011, 177(3-4):378-382.

52. Kváč M, Kouba M, Vitovec J: Age-related and housing-dependence of Cryptosporidium infection of calves from dairy and beef herds in South Bohemia, Czech Republic. Vet Parasitol 2006, 137(3-4):202-209.

53. Keshavarz A, Haghighi A, Athari A, Kazemi B, Abadi A, Mojarad EN: Prevalence and molecular characterization of bovine Cryptosporidium in Qazvin province, Iran. Vet Parasitol 2009, 160(3-4):316-318.

54. Muhid A, Robertson I, Ng J, Ryan UM: Prevalence of and management factors contributing to Cryptosporidium sp. infection in pre-weaned and post-weaned calves in Johor, Malaysia. Exp Parasitol 2011, 127(2):534-538.

55. Santín M, Trout JM, Xiao L, Zhou L, Greiner E, Fayer R: Prevalence and age-related variation of Cryptosporidium species and genotypes in dairy calves. Vet Parasitol 2004, 122(2):103-117.

56. Langkjaer RB, Vigre H, Enemark HL, Maddox-Hyttel C: Molecular and phylogenetic characterization of Cryptosporidium and Giardia from pigs and cattle in Denmark. Parasitology 2007, 134(Pt 3):339-350.

57. Khan SM, Debnath C, Pramanik AK, Xiao L, Nozaki T, Ganguly S: Molecular characterization and assessment of zoonotic transmission of Cryptosporidium from dairy cattle in West Bengal, India. Vet Parasitol 2010, 171(1-2):41-47.

58. Robinson G, Chalmers RM, Stapleton C, Palmer SR, Watkins J, Francis C, Kay D: A whole water catchment approach to investigating the origin and distribution of Cryptosporidium species. J App/ Microbiol 2011, 111(3):717-730

59. Amer S, Zidan S, Feng Y, Adamu H, Li N: Identity and public health potential of Cryptosporidium spp. in water buffalo calves in Egypt. Vet Parasitol 2013, 191(1-2):123-127.

60. Venu R, Latha BR, Basith SA, Raj GD, Sreekumar C, Raman M: Molecular prevalence of Cryptosporidium spp. in dairy calves in Southern states of India. Vet Parasitol 2012, 188(1-2):19-24.

61. Mallinath RHK, Chikkachowdappa PG, Gowda AKJ, D'Souza PE: Studies on the prevalence of cryptosporidiosis in bovines in organized dairy farms in and around Bangalore, South India. Vet Arhiv 2009, 5:461.

62. Nasir A, Avais M, Khan MS, Ahmad N: Prevalence of Cryptosporidium parvum infection in Lahore (Pakistan) and its association with diarrhea in dairy calves. Int J Agr Biol 2009, 11(2):221-224.

63. Fayer R, Santín M, Trout JM, Greiner E: Prevalence of species and genotypes of Cryptosporidium found in 1-2-year-old dairy cattle in the eastern United States. Vet Parasitol 2006, 135(2):105-112.

64. Trotz-Williams LA, Martin DS, Gatei W, Cama V, Peregrine AS, Martin SW, Nydam DV, Jamieson F, Xiao L: Genotype and subtype analyses of Cryptosporidium isolates from dairy calves and humans in Ontario. Parasitol Res 2006, 99(4):346-352.

65. Thompson HP, Dooley JS, Kenny J, McCoy M, Lowery CJ, Moore JE, Xiao L: Genotypes and subtypes of Cryptosporidium spp. in neonatal calves in Northern Ireland. Parasitol Res 2007, 100(3):619-624.

66. Amer S, Zidan S, Adamu H, Ye J, Roellig D, Xiao L, Feng Y: Prevalence and characterization of Cryptosporidium spp. in dairy cattle in Nile River delta provinces, Egypt. Exp Parasitol 2013, 135(3):518-523.

67. Geurden T, Berkvens D, Martens C, Casaert S, Vercruysse J, Claerebout E: Molecular epidemiology with subtype analysis of Cryptosporidium in calves in Belgium. Parasitology 2007, 134(14):1981-1987.
68. Feng Y, Ortega Y, He G, Das P, Xu M, Zhang X, Fayer R, Gatei W, Cama V, Xiao L: Wide geographic distribution of Cryptosporidium bovis and the deer-like genotype in bovines. Vet Parasitol 2007, 144(1-2):1-9.

69. Zhang W, Wang R, Yang FK, Zhang L, Cao J, Zhang X, Ling H, Liu A, Shen Y: Distribution and genetic characterizations of Cryptosporidium spp. in pre-weaned dairy calves in Northeastern China's Heilongjiang Province. PLOS ONE 2013, 8(1):1-6.

70. Maikai BV, Umoh JU, Kwaga JK, Lawal IA, Maikai VA, Cama V, Xiao L: Molecular characterization of Cryptosporidium spp. in native breeds of cattle in Kaduna State, Nigeria. Vet Parasitol 2011, 178(3-4):241-245.

71. Silverlås C, Näslund K, Björkman C, Mattsson JG: Molecular characterisation of Cryptosporidium isolates from Swedish dairy cattle in relation to age, diarrhoea and region. Vet Parasitol 2010, 169(3-4):289-295.

72. Becher KA, Robertson ID, Fraser DM, Palmer DG, Thompson RCA: Molecular epidemiology of Giardia and Cryptosporidium infections in dairy calves originating from three sources in Western Australia. Vet Parasitol 2004, 123(1-2):1-9.

73. Ng J, Yang R, McCarthy S, Gordon C, Hijjawi N, Ryan UM: Molecular characterization of Cryptosporidium and Giardia in pre-weaned calves in Western Australia and New South Wales. Vet Parasitol 2011, 176(2-3):145-150.

74. Appelbee AJ, Frederick LM, Heitman TL, Olson ME: Prevalence and genotyping of Giardia duodenalis from beef calves in Alberta, Canada. Vet Parasitol 2003, 112(4):289-294.

75. Trout JM, Santín M, Greiner E, Fayer R: Prevalence of Giardia duodenalis genotypes in pre-weaned dairy calves. Vet Parasitol 2004, 124(3-4):179-186.

76. Trout JM, Santín M, Greiner EC, Fayer R: Prevalence and genotypes of Giardia duodenalis in 1-2 year old dairy cattle. Vet Parasitol 2006, 140(3-4):217-222.

77. Fayer $R$, Santín M, Macarisin D: Detection of concurrent infection of dairy cattle with Blastocystis, Cryptosporidium, Giardia, and Enterocytozoon by molecular and microscopic methods. Parasitol Res 2012, 111(3):1349-1355.

78. Cardona GA, Carabin H, Goni P, Arriola L, Robinson G, Fernandez-Crespo JC, Clavel A, Chalmers RM, Carmena D: Identification and molecular characterization of Cryptosporidium and Giardia in children and cattle populations from the province of Alava, North of Spain. Sci Total Environ 2011, 412-413:101-108.

79. Hamnes IS, Gjerde B, Robertson L: Prevalence of Giardia and Cryptosporidium in dairy calves in three areas of Norway. Vet Parasitol 2006, 140(3-4):204-216.

80. Bhat SA, Juyal PD, Singla LD: Prevalence of cryptosporidiosis in neonatal buffalo calves in Ludhiana District of Punjab, India. Asian J Anim Vet Adv 2012, 7:512-520.

81. Feng Y, Raj Karna S, Dearen TK, Singh DK, Adhikari LN, Shrestha A, Xiao L: Common occurrence of a unique Cryptosporidium ryanae variant in zebu cattle and water buffaloes in the buffer zone of the Chitwan National Park Nepal. Vet Parasitol 2012, 185(2-4):309-314.

82. El-Khodery SA, Osman SA: Cryptosporidiosis in buffalo calves (Bubalus bubalis): prevalence and potential risk factors. Trop Anim Health Prod 2008, 40(6):419-426.

doi:10.1186/1756-3305-7-75

Cite this article as: Abeywardena et al:: First molecular characterization of Cryptosporidium and Giardia from bovines (Bos taurus and Bubalus bubalis) in Sri Lanka: unexpected absence of $C$. parvum from pre-weaned calves. Parasites \& Vectors 2014 7:75.

\section{Submit your next manuscript to BioMed Central and take full advantage of:}

- Convenient online submission

- Thorough peer review

- No space constraints or color figure charges

- Immediate publication on acceptance

- Inclusion in PubMed, CAS, Scopus and Google Scholar

- Research which is freely available for redistribution 